\title{
Anxiolytic and Anti-Stress Effects of Brain Prolactin: Improved Efficacy of Antisense Targeting of the Prolactin Receptor by Molecular Modeling
}

\author{
Luz Torner, Nicola Toschi, Agnes Pohlinger, Rainer Landgraf, and Inga D. Neumann \\ Max Planck Institute of Psychiatry, 80804 Munich, Germany
}

We provide the first evidence that prolactin is a neuromodulator of behavioral and neuroendocrine stress coping in the rat. In virgin female and male rats, intracerebral infusion of ovine prolactin (oPRL) into the lateral cerebral ventricle (intracerebroventricular) exerted an anxiolytic effect on the elevated plusmaze in a dose-dependent manner $(0.1$ and $1.0 \mu \mathrm{g} / 5 \mu \mathrm{l} ; p<$ $0.01)$. In contrast, downregulation of the expression of the long form of brain prolactin receptors by chronic intracerebroventricular infusion of an antisense oligodeoxynucleotide (ODN) (osmotic minipump, $0.5 \mu \mathrm{g} \cdot 0.5 \mu \mathrm{l}^{-1} \cdot \mathrm{hr}^{-1} ; 5 \mathrm{~d}$ ) increased anxiety-related behavior on the plus-maze compared with mixed bases-treated and vehicle-treated rats $(p<0.01)$, again demonstrating an anxiolytic effect of PRL acting at brain level. Furthermore, in jugular vein-catheterized female rats, the stress-induced increase of corticotropin secretion was decreased after chronic intracerebroventricular infusion of oPRL (osmotic minipump, $1.0 \mu \mathrm{g} \cdot 0.5 \mu \mathrm{l}^{-1} \cdot \mathrm{hr}^{-1} ; p<0.05$ ) and, in contrast, was further elevated by antisense targeting of the brain prolactin receptors ( $p<0.01$ ). This provides evidence for a receptor-mediated attenuation of the responsiveness of the hypothalamo-pituitary-adrenal (HPA) axis by prolactin. The antisense ODN sequence was selected on the basis of secondary structure molecular modeling of the target mRNA to improve antisense ODN-mRNA hybridization. Receptor autoradiography confirmed the expected improvement in the efficacy of downregulation of prolactin receptor expression [empirically designed antisense, 30\%; $p>0.05$, not significant; adjustment of target position after mRNA modeling, 72\%; $p<0.05)$. Taken together, prolactin acting at brain level has to be considered as a novel regulator of both emotionality and HPA axis reactivity.

Key words: ACTH; anxiety; choroid plexus; plus-maze; HPA axis; $m R N A$ secondary structure
Anxiety is a complex trait that has evolved to help animals evaluate and circumvent potentially dangerous situations. The neurobiological basis of anxiety-related behavior involves various neuropeptidergic systems, including corticotropin-releasing hormone (CRH) (Mitchell, 1999), neuropeptide Y (Wahlestedt et al., 1993), substance P (Kramer et al., 1998), and vasopressin (Liebsch et al., 1996). Under pathological conditions of hyperanxiety (Holsboer and Barden, 1996) or in rats displaying high innate anxietyrelated behavior (Landgraf et al., 1999), an aberrant hyperactivity of the hypothalamic-pituitary-adrenal (HPA) axis has been described, indicating a close interaction between emotionality and neuroendocrine systems.

Prolactin (PRL), in addition to its role during lactation, may influence both emotional responses and HPA axis activity. On the basis of different techniques, this neuropeptide has been shown to participate in the regulation of maternal behavior (Bridges et al., 1990; Lucas et al., 1998), grooming (Drago et al., 1983), and food intake in mammalian (Noel and Woodside, 1993) and nonmammalian species ( $\mathrm{Li}$ et al., 1995). A possible involvement of PRL in stress response mechanisms is suggested by the findings that (1) PRL is released into the blood from pituitary

\footnotetext{
Received Oct. 16, 2000; revised Jan. 16, 2001; accepted Jan. 29, 2001.

This work was supported by Deutsche Forschungsgemeinschaft Grant Ne 465 (I.D.N., N.T., A.P., L.T.) and CONACyT (Mexico) (L.T.). We thank P. Lörscher for technical support, Dr. C. Probst for discussing the antisense design, Dr. C. Jacob for providing the secondary structure prediction computer program (SEQFOLD), and Dr. J. A. Russell for critical comments on a previous version of this manuscript.

Correspondence should be addressed to Inga D. Neumann, Max Planck Institute of Psychiatry, Kraepelinstrasse 2, D 80804 Munich, Germany. E-mail: INEU@ MPIPSYKL.MPG.DE.
}

Copyright (C) 2001 Society for Neuroscience $\quad 0270-6474 / 01 / 213207-08 \$ 15.00 / 0$ lactotroph cells in response to exposure to different stressors (Neill, 1970; Seggie and Brown, 1975), (2) chronic stress induced the expression of the long form of the PRL receptors (PRL-R) in choroid plexus cells (Fujikawa et al., 1995), and (3) administration of PRL into the cerebral ventricles prevented the stressinduced formation of gastric ulcers and showed antidepressant effects during forced swimming (Drago et al., 1985, 1990). Furthermore, neuroendocrine stress responses were found to be attenuated in states of hyperprolactinemia (Schlein et al., 1974; Carter and Lightman, 1987). However, evidence for a receptormediated regulation of behavioral and neuroendocrine stress coping by PRL is still missing, possibly because of the lack of a specific PRL-R antagonist.

The PRL gene is expressed in several hypothalamic areas (DeVito et al., 1992; Emanuele et al., 1992), including the paraventricular nucleus (PVN) (Clapp et al., 1994). PRL-like immunoreactive fibers innervate, among others, the parvocellular portion of the PVN (Paut-Pagano et al., 1993) in which neurons synthesizing the adrenocorticotropic hormone (ACTH) secretagogue CRH are located (Merchenthaler et al., 1982). PRL-like immunoreactive fibers have also been found in extrahypothalamic limbic brain regions, such as the bed nucleus of stria terminalis and the amygdala (Paut-Pagano et al., 1993), which are known to be critically involved in the regulation of emotionality (Charney et al., 1998). Both the long and short forms of the PRL-R have been mapped in these brain areas (Chiu and Wise, 1994; Bakowska and Morrell, 1997). However, the highest density of PRL-R, with predominance of the long form, exists in choroid plexus cells (Crumeyrolle-Arias et al., 1993; Bakowska and Morrell, 1997) in which active uptake of blood PRL into the brain 
takes place (Walsh et al., 1987), raising the possibility of a coordinated action in the brain of both peripheral and brain PRL.

In this study, to reveal receptor-mediated effects of PRL on anxiety-related behavior and on basal as well as stress-induced HPA axis activity in rats, we used complementary methodological approaches, including acute and chronic intracerebroventricular or intravenous infusion of ovine PRL (oPRL) into the lateral cerebral ventricle. Furthermore, because of the lack of a selective PRL-R antagonist, antisense oligodeoxynucleotides (ODNs) targeting the PRL-R mRNA (long form) were administered intracerebroventricularly to efficiently and transiently downregulate intracerebral receptor expression. Improved effectiveness of an antisense ODN sequence based on secondary structure prediction (Ho et al., 1998; Cairns et al., 1999) of the PRL-R mRNA molecule was confirmed for the first time in vivo.

Preliminary results of this study have been published previously in abstract form (Torner and Neumann, 1998; Torner et al., 1999).

\section{MATERIALS AND METHODS}

Virgin female (250-280 gm body weight) and male (280-300 gm) Wistar rats were maintained under standard laboratory conditions. Surgical procedures were performed under halothane anesthesia, after which animals were housed individually and handled daily to reduce nonspecific stress responses on the experimental day. Behavioral and neuroendocrine studies were performed between 9:00 A.M. and 12:00 P.M., at least $4 \mathrm{~d}$ after surgery. All experimental procedures were approved by the local government of Bavaria, Germany.

Acute intracerebroventricular oPRL administration. A guide cannula (21 ga) was stereotaxically cemented above the right lateral ventricle $(0.8 \mathrm{~mm}$ behind bregma, $1.6 \mathrm{~mm}$ lateral, $1.8 \mathrm{~mm}$ below the skull) (Paxinos and Watson, 1986) of virgin female and male rats. Five days after surgery, rats were administered oPRL (0.1 or $1 \mu \mathrm{g} / 5 \mu \mathrm{l}$, i.c.v.; Sigma-Aldrich, Steinheim, Germany) or vehicle (5 $\mu$ l of Ringer's solution, $\mathrm{pH} 7.4$ ) under stress-free conditions via an intracerebroventricular inf usion cannula (25 ga) inserted into the guide cannula $2 \mathrm{hr}$ earlier and attached to the inf usion microsyringe via 40-cm-long polyethylene tubings to allow remote injection into the freely moving, mostly sleeping animals over $30 \mathrm{sec}$. Ten minutes after the injection, rats were subjected to the elevated plus-maze (EPM; day 1), forced swim (day 3), and/or open-field test (day 7).

Acute intravenous oPRL administration. Virgin female rats were implanted with a chronic jugular vein catheter as described previously (Neumann et al., 1998). Five days thereafter, the catheter was attached to an infusion line, and oPRL $\left(5 \mathrm{mg} \cdot \mathrm{kg}^{-1} \cdot 0.5 \mathrm{ml}^{-1}\right)$ or vehicle $(0.5$ $\mathrm{ml} / \mathrm{kg}$ ) was infused intravenously. After $20 \mathrm{~min}$, the animals were tested on the EPM.

Acute intraperitoneal diazepam administration. To compare the anxiolytic effect of PRL with that of an established anxiolytic drug (Fernandez-Guasti and Picazo, 1997; Liebsch et al., 1998), we injected virgin female and male rats with either diazepam $(1 \mathrm{mg} / \mathrm{kg}$, i.p. $)$ or vehicle $(1 \mathrm{ml} / \mathrm{kg}) 30 \mathrm{~min}$ before exposure to the EPM and behavioral recordings.

Chronic intracerebroventricular oPRL or PRL-R antisense ODN administration. Osmotic minipumps (model 1007D; Alzet Corp., Palo Alto, CA) filled with oPRL $\left(1 \mu \mathrm{g} \cdot 0.5 \mu \mathrm{l}^{-1} \cdot \mathrm{hr}^{-1}\right)$, PRL-R antisense ODN $\left(0.5 \mu \mathrm{g} \cdot 0.5 \mu \mathrm{l}^{-1} \cdot \mathrm{hr}^{-1}\right)$, mixed bases ODN $(0.5 \mu \mathrm{g} \cdot 0.5$ $\mu \mathrm{l}^{-1} \cdot \mathrm{hr}^{-1}$ ), or vehicle (Ringer's solution; $0.5 \mu \mathrm{l} / \mathrm{hr}$ ) were connected to an intracerebroventricular infusion cannula positioned into the right lateral ventricle of virgin female rats $5 \mathrm{~d}$ before anxiety-related behavior was tested on the EPM.

Jugular vein catheter. To study the effect of acute or chronic intracerebroventricular oPRL treatment or chronic intracerebroventricular PRL-R antisense treatment on HPA axis reactivity, we also implanted rats with a jugular vein catheter filled with sterile saline $(0.9 \%)$ containing gentamicin (30,000 IU/ml; Centravet, Bad Bentheim, Germany). After acute intracerebroventricular administration or $5 \mathrm{~d}$ of intracerebroventricular treatment, blood samples were taken under basal conditions and in response to an emotional stressor (EPM). Plasma ACTH was measured by radioimmunoassay using commercially available kits (ICN Biomedicals, Costa Mesa, CA).

Elevated plus-maze. The EPM test was used to assess the emotional state and as a mild emotional stressor (novel environment) in our experiments. This test is based on the creation of a conflict between the exploratory drive of the rat and its innate fear of open and exposed areas; it has been validated for the detection of emotional responses to anxiogenic and anxiolytic substances (Pellow et al., 1985). Thus, increased open-arm exploration indicates reduced anxiety-related behavior. The EPM consists of a plus-shaped platform elevated $70 \mathrm{~cm}$ above the floor. Two of the opposing arms $(50 \times 10 \mathrm{~cm})$ are closed by $40-\mathrm{cm}$-high side and end walls, whereas the other two arms have no walls (open arms). At the beginning of the test, the rats were placed on the central area $(10 \times$ $10 \mathrm{~cm}$ ) of the maze. The following parameters of anxiety-related behavior were recorded by means of a video camera-computer setup during the 5 min testing period: (1) entries into open arms (ratio of open-arm entries to total number of entries into all arms), (2) time spent on the open arms (ratio of time spent on open arms to total time spent on all arms), (3) overall activity (total number of entries into closed arms), and (4) number of full entries into the open arms (Liebsch et al., 1998).

Forced swim test. Forced swimming represents an ethologically relevant physical and emotional stressor for rats (Abel, 1994) and was used to assess active versus passive stress-coping strategies and to reveal antidepressive drug effects (Marti and Armario, 1993). Two days after exposure on the EPM, rats were forced to swim for $10 \mathrm{~min}$, and their behavior was scored by a trainer-observer pressing preset PC keys. The following behaviors were noted: (1) time spent struggling, defined as strongly moving all four limbs with the front paws breaking the water surface or scratching the tank wall; (2) time spent swimming, defined as moving all four limbs, swimming around the tank, or diving; (3) time spent floating, defined as remaining immobile with only occasional slight movements to keep the body balanced and the nose above water; and (4) latency until first floating.

Open-field test. The open-field test has been used to assess the effect of intracerebroventricular PRL on the locomotor activity of the rats. During the $15 \mathrm{~min}$ exposure time in the gray plastic box $(60 \times 60 \times 40 \mathrm{~cm})$, the total path traveled was recorded by a video setup.

To determine the stage of the estrous cycle, cytological examinations from vaginal smears were monitored after completion of the respective experiments. Behavioral scores of animals differing in cycle stage showed no significant differences within the same experimental group. Thus, results were compiled and analyzed regardless of estrous cycle.

Antisense and mixed bases ODN sequences. All antisense ODNs were endcapped phosphorothioated (MWG-Biotech AG, Ebersberg, Germany). A mixture of two antisense (AS) ODNs (AS1; 5'-CAC TTC CTG CAA AGG ACG-3'; 5'-CTG CCA TAC CAG AGG CTG-3') or mixed bases ODN (5'-ACA CGT CTC GAA GAG CGA-3') was applied initially in behavioral studies. These antisense ODNs were complementary to nucleotides 62-79 and 82-99 (Fig. 1A) of the mRNA coding for the PRL-R (Shirota et al., 1990; GenBank accession no. M57668). Antisense ODN design was then improved on the basis of twodimensional molecular modeling results (AS2; 5'-GTA AGT CAG TGA ATA ATT GG-3'; mixed bases ODN, 5'-AACA CGT CTC GAA GAG CGAA- $\left.3^{\prime}\right)$. AS2 was complementary to nucleotides $354-373$ of the mRNA coding for the PRL-R (Fig. $1 B$ ) and was used for all neuroendocrine and behavioral studies presented here.

Autoradiography. The efficiency of PRL-R antisense ODNs in downregulating brain PRL-R was analyzed by receptor autoradiography. Brains were collected $1 \mathrm{hr}$ after stress exposure and immediately frozen until processing. Mounted serial coronal $20 \mu \mathrm{m}$ cryostat sections were treated as described by Crumeyrolle-Arias et al. (1993), and all sections were processed in the same assay (eight sections per rat). Briefly, mounted sections were preincubated in Tris buffer $\left(50 \mathrm{~mm}, 2 \mathrm{mM} \mathrm{CaCl}_{2}\right.$, $5 \mathrm{~mm} \mathrm{KCl}, \mathrm{pH} 7.4$ ), rinsed twice (Tris $50 \mathrm{~mm}$ ), and air dried. Then sections were incubated with $0.6 \mathrm{nM}{ }^{125} \mathrm{I}$-human growth hormone (DuPont NEN, Wilmington, DE) in Tris buffer $(120 \mathrm{~mm}$ and $0.2 \%$ bovine serum albumin, $\mathrm{pH} 7.4$, at $20^{\circ} \mathrm{C}, 1 \mathrm{hr}$ ), rinsed twice, dipped in deionized water, and air dried. Nonspecific binding was determined by adding $1 \mu \mathrm{M}$ oPRL. Labeled slides were exposed to Biomax MR films (Kodak, Rochester, NY) in x-ray cassettes for $18 \mathrm{~d}$. Quantitative assessment of autoradiograms was performed using image analysis software (OPTIMAS, Optimas Corp.; $10 \times$ magnification; $10 \mathrm{~mm}$ objective). Optical density values of autoradiograms (based on 256 grayscale units), averaged over the left or right choroid plexus (1.0 $\mathrm{mm}$ behind bregma), were converted into relative label concentrations by logarithmic transformation (natural logarithm), because the degree of darkening of the film is known to be logarithmically related to the amount of exposing label. Nonspecific binding values were subtracted from total binding after adjusting the backgrounds to similar values. 


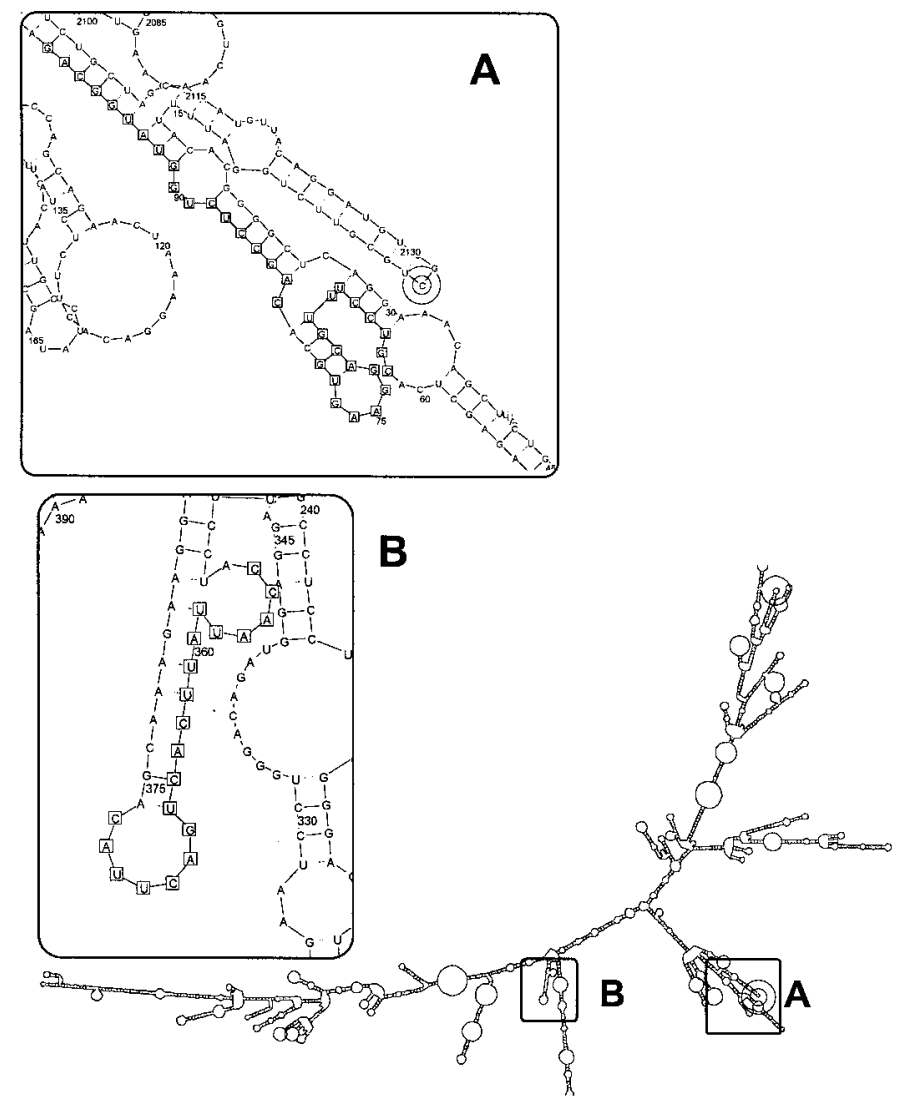

Figure 1. Secondary structure of mRNA coding for the rat PRL-R as predicted by sequential energy minimization. Noncanonical base pairs are allowed. The regions selected for targeting are magnified. A, Two antisense ODNs selected empirically, used also in comparative autoradiographic experiments. $B$, Antisense ODNs selected on the basis of molecular modeling, used in behavioral and neuroendocrine experiments. The beginning of the sequence is marked by two concentric circles. The simulation strategy is based on a homogeneous Markovian jump process that considers each transcription step. The state space of interest is the set of structures constructible on the part of the mRNA already transcribed. A formula permitting the computation of the structures' probabilities at the end of the mRNA transcription is derived and successively approximated to reduce the size of the state space. This permits the design of a prediction algorithm (Breton et al., 1997).

Statistical analysis. Values are expressed as the mean \pm SEM. One-way ANOVA (behavioral data, autoradiography) or two-way ANOVA (factors time $\times$ treatment; ACTH) followed by Newman-Keuls test (females, EPM and ACTH data, autoradiography) or Fisher (males, EPM data) post hoc test were used as indicated (GB-Stat 6.0; Dynamic Microsystems, Silver Spring, MD). $p \leq 0.05$ was considered statistically significant.

\section{RESULTS}

\section{Behavioral effects of oPRL}

Compared with vehicle-treated controls, intracerebroventricular oPRL resulted in a significant and dose-dependent decrease in anxiety-related behavior in both female and male rats on the EPM (Fig. 2A,B). PRL affected the different measures of anxietyrelated behavior, including the percentage of entries into [ANOVA, females, $F_{(2,24)}=19.6 ; p<0.0001$; males, $F_{(2,17)}=$ $3.38 ; p=0.05$ ], the percentage of time on [females, $F_{(2,24)}=8.14$; $p=0.002$; males, $\left.F_{(2,17)}=2.53 ; p=0.10\right]$, and the number of full entries into [females, $F_{(2,24)}=7.98 ; p=0.002$; males, $F_{(2,17)}=$ 2.08; $p=0.15$ ] the open arms of the EPM.

Systemic (intravenous) administration of oPRL to female rats
A $q$ icv $\square$ vehicle (8) $\square 0.1 \mu \mathrm{g}$ oPRL (6) $\square 1 \mu \mathrm{g}$ oPRL (8)
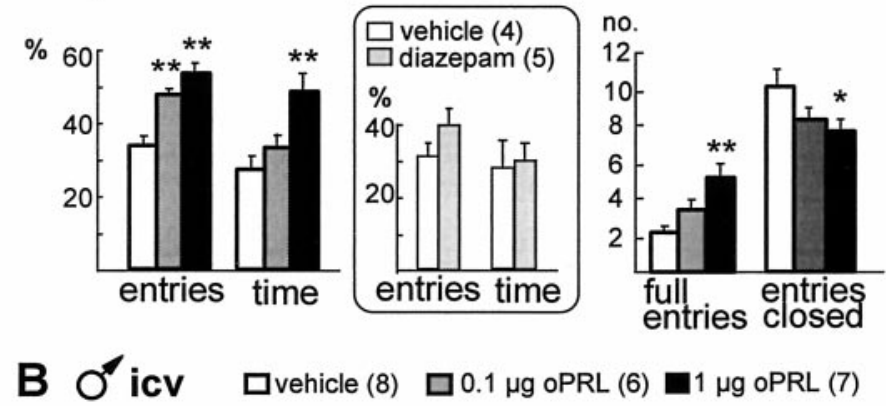

$\square$ vehicle (8) $\square 0.1 \mu \mathrm{g}$ oPRL (6)
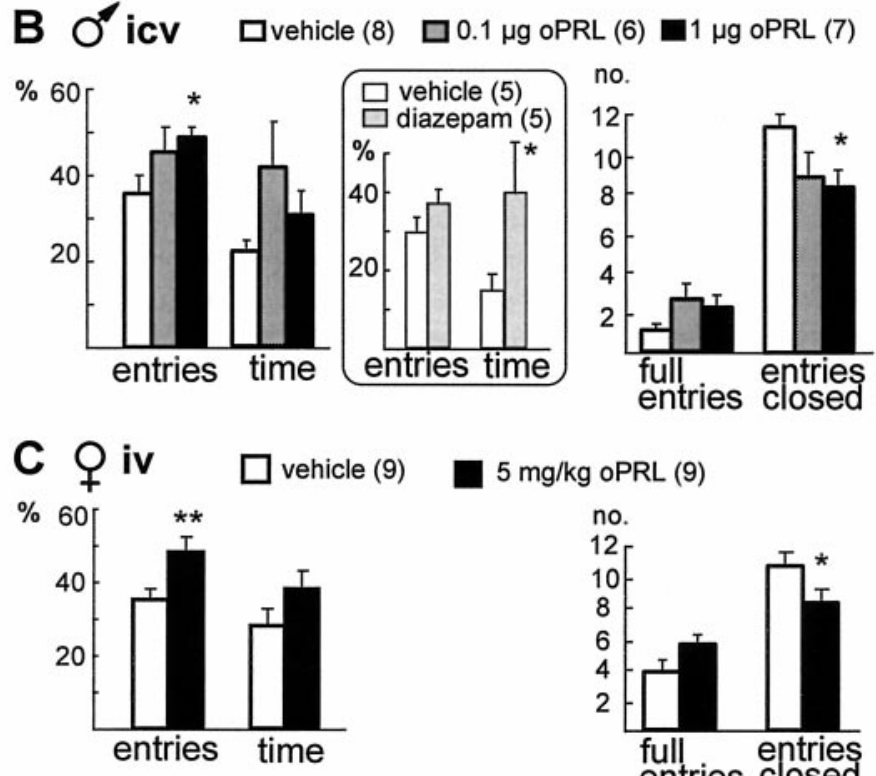

$5 \mathrm{mg} / \mathrm{kg}$ oPRL (9)

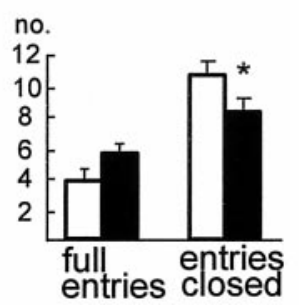

Figure 2. Behavioral parameters on the EPM of female and male rats treated with intracerebroventricular or intravenous oPRL. $A, B$, Acute intracerebroventricular oPRL administered $10 \mathrm{~min}$ before EPM exposure decreased the anxiety-related behavior in a dose-dependent manner in virgin female $(A)$ or male $(B)$ rats. For comparison, an anxiolytic effect could also be revealed $30 \mathrm{~min}$ after injection of diazepam $(1 \mathrm{mg} / \mathrm{kg}$, i.p.) in male but not female rats (insets). $C$, Acute intravenous oPRL administered $20 \mathrm{~min}$ before EPM also decreased anxiety-related behavior in female rats. The percentage of entries into (entries) and the time spent on (time) the open arms to overall arm entries and time, respectively, and the number of full entries into the open arms of the EPM are given as indicators of anxiety-related behavior. The number of entries into the closed arms (entries closed) is given as an indicator of locomotor activity. Data are the mean \pm SEM. ${ }^{*} p<0.05,{ }^{*} p<0.01$ versus vehicle.

at doses resembling stress-induced plasma PRL concentrations (Neill, 1970) also resulted in reduced anxiety, because the percentage of entries into the open arms of the EPM was significantly increased $\left[F_{(1,16)}=16.3 ; p=0.001\right]$ (Fig. $2 C$ ).

For comparison of the anxiolytic effect of oPRL, we tested the established anxiolytic drug diazepam ( $1 \mathrm{mg} / \mathrm{kg}$, i.p.). Diazepam significantly reduced anxiety-related behavior on the EPM in male (percentage of time on the open arms; $p<0.05$ ), but not female rats compared with vehicle treatment (Fig. $2 A, B$, insets).

After intracerebroventricular $(1 \mu \mathrm{g}$; both males and females; $p<0.05)$ as well as intravenous $(p<0.05)$ oPRL treatment, the locomotor activity was decreased, as indicated by a reduced number of entries into the closed arms (Fig. 2, right). This finding was confirmed in the open-field test because oPRL reduced the distance traveled during the 15 min exposure $\left[F_{(1,11)}=4.80 ; p=\right.$ 0.035] (Table 1). In contrast, during the 10 min forced swimming, 


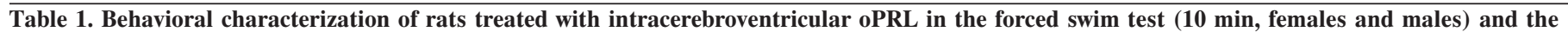
open field (15 min, females)

\begin{tabular}{|c|c|c|c|c|}
\hline & \multicolumn{2}{|l|}{ Vehicle } & \multicolumn{2}{|l|}{ Prolactin } \\
\hline & Female & Male & Female & Male \\
\hline Forced swim & $n=8$ & $n=10$ & $n=8$ & $n=11$ \\
\hline Struggling (sec) & $108 \pm 33.0$ & $79.3 \pm 9.9$ & $126 \pm 61.3$ & $114 \pm 12.6^{*}$ \\
\hline Floating (sec) & $16.0 \pm 15.5$ & $12.2 \pm 5.0$ & $5.2 \pm 3.2$ & $6.8 \pm 2.5$ \\
\hline Latency (sec) & $224 \pm 124$ & $167 \pm 50.6$ & $416 \pm 238^{*}$ & $293 \pm 58.9$ \\
\hline Open field & $n=6$ & & $n=7$ & \\
\hline Distance $(\mathrm{cm})$ & $5634 \pm 261$ & & $4354 \pm 395^{*}$ & \\
\hline
\end{tabular}

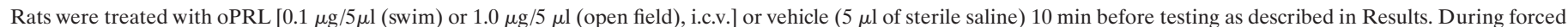

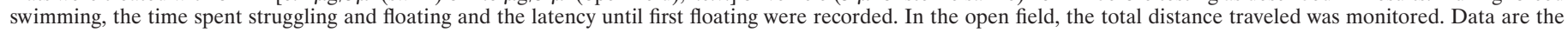
means \pm SEM. ${ }^{*} p<0.05$ versus vehicle.

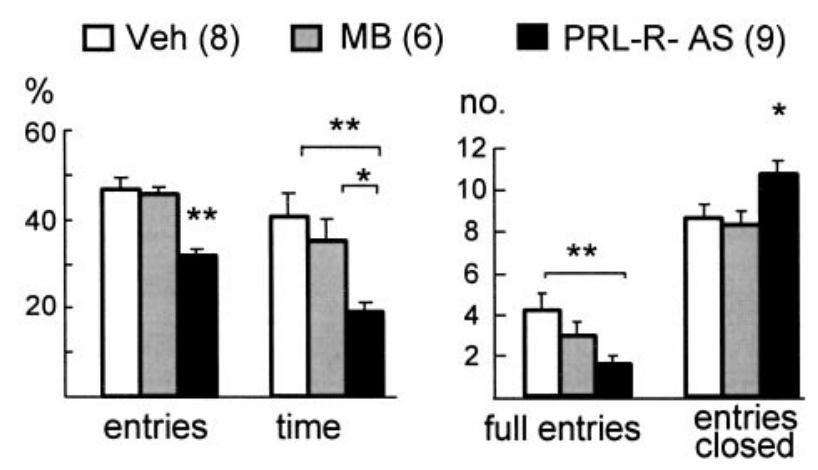

Figure 3. Anxiety-related behavior on the EPM after downregulation of brain PRL-R by antisense targeting. Anxiety-related behavior was increased after $5 \mathrm{~d}$ of chronic intracerebroventricular infusion of PRL-R antisense $(P R L-R-A S)$ ODN compared with vehicle (Veh)-treated or mixed bases ODN $(M B)$-treated virgin female rats, as shown by a decrease in the percentage of entries into, the percentage of time in, and the number of full entries into the open arms of the EPM. Data are the mean \pm SEM. ${ }^{*} p<0.05,{ }^{*} p<0.01$

oPRL-treated rats showed a more active coping strategy as revealed by an increased time spent struggling $\left[F_{(1,19)}=4.68 ; p=\right.$ 0.043 ; males $]$ and a prolonged latency to floating $\left[F_{(1,14)}=4.69\right.$; $p=0.048$; females] (Table 1).

\section{Antisense ODN targeting of brain PRL-R: effects on anxiety-related behavior}

Compared with vehicle-treated or mixed bases ODN-treated controls (which did not differ from each other), downregulation of PRL-R expression by antisense targeting significantly increased the anxiety-related behavior on the EPM in female rats, because both the percentage of entries into [ANOVA; $F_{(2,18)}=13.2 ; p=$ $0.001]$ and the percentage of time on $\left[F_{(2,18)}=6.50 ; p=0.007\right]$ the open arms of the EPM were reduced (Fig. 3). Also, the number of full entries into the open arms was reduced $\left[F_{(2,18)}=\right.$ 3.18; $p=0.041)$, whereas locomotor activity was increased in PRL-R antisense-treated rats as indicated by an increased number of entries into the closed arms $\left[F_{(2,18)}=4.52 ; p=0.02\right]$.

\section{Inhibition of neuroendocrine responses to stressors by PRL: involvement of brain PRL-R}

After $5 \mathrm{~d}$ of chronic intracerebroventricular inf usion of vehicle or oPRL, two-way ANOVA did not reveal significant differences in basal and stress-induced ACTH between groups [factor time, $F_{(3,42)}=36.9 ; p<0.0001$; factor treatment, $F_{(1,14)}=0.62 ; p=$ $0.44]$. Separate statistics performed on basal hormone concentrations [one-way ANOVA; $F_{(1,14)}=5.05 ; p=0.04$ ] as well as the stress-induced increase in hormone secretion as a percentage of basal levels $\left[F_{(1,14)}=6.03 ; p=0.02\right]$ revealed increased basal ACTH plasma concentrations and an attenuated stress-induced increase in ACTH secretion in oPRL-treated rats (Fig. 4A).

Downregulation of PRL-R expression by intracerebroventricular infusion of PRL-R antisense ODN significantly affected ACTH secretion [interaction time $\times$ treatment; $F_{(6,57)}=2.81$; $p=0.018]$. Although basal ACTH plasma levels did not differ between groups, antisense ODN treatment further elevated stress-induced ACTH secretion, compared with vehicle-treated and mixed bases-treated rats, 5 and 15 min after stressor exposure (Fig. 4B).

Acute intracerebroventricular oPRL $(0.1$ and $1.0 \mu \mathrm{g} / 5 \mu \mathrm{l})$ failed to alter basal or stress-induced ACTH plasma levels compared with vehicle-treated controls [factor time, $F_{(3,57)}=23.1$; $p<0.0001$; factor treatment, $F_{(2,19)}=0.10 ; p=0.9$; data not shown].

\section{Antisense ODN design and receptor autoradiography}

Three different antisense ODNs were used in these studies; they differed in the position of the target sites within the mRNA molecule coding for the long form of the PRL-R (Fig. 1).

For comparative purposes, a mixture of two antisense ODNs (see Materials and Methods) directed against two target sites upstream of the initiation codon of the PRL-R mRNA (Fig. 1B) was used initially. This resulted in only a trend toward a reduction (29\% vs vehicle and $39 \%$ vs mixed bases) in PRL-R binding at the choroid plexus of the right cerebral ventricle [ANOVA; $F_{(2,13)}=$ $0.58 ; p=0.56]$ (Fig. 5A).

For behavioral and neuroendocrine studies, we selected the mRNA target site on the basis of a kinetic folding simulation (Breton et al., 1997) aimed at predicting the secondary structure of the PRL-R mRNA. Following the finding that regions which yield high hybridization efficiency include part of an open loop and a complete stem (Mir and Southern, 1999), we selected a portion of the target mRNA molecule that was predicted to meet these criteria (Fig. 1 $A$ ). Indeed, receptor autoradiography revealed a significant downregulation of receptor binding at the choroid plexus of the right ventricle of $72 \%$, compared with both vehicle and mixed bases $\left[F_{(6,14)}=2.93 ; p<0.05\right]$ (Fig. $\left.5 B, C\right)$.

\section{DISCUSSION}

Using complementary approaches, including application of the receptor ligand and downregulation of PRL-R expression by antisense targeting, we provided the first evidence that PRL acts as an endogenous anxiolytic and reduces HPA axis responses to stress in the rat. Prediction of PRL-R mRNA secondary structure 

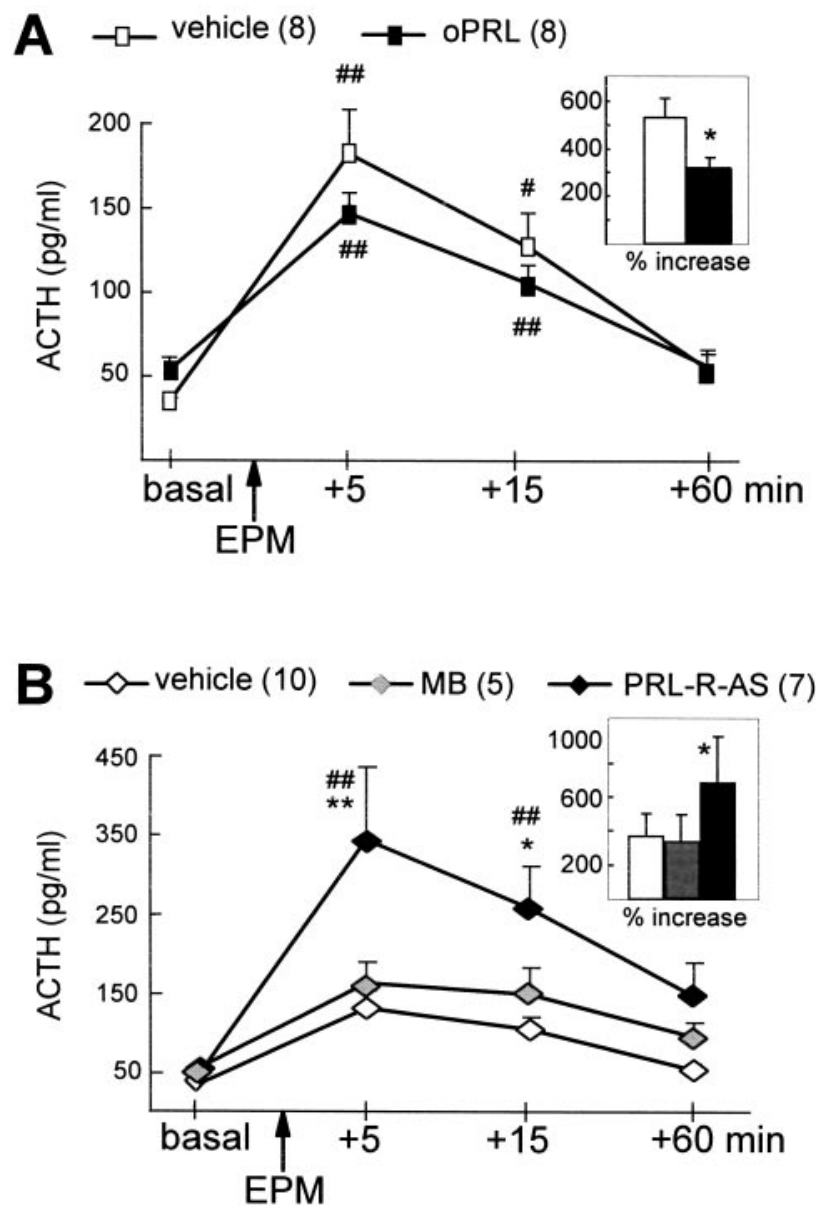

Figure 4. Plasma ACTH concentrations after chronic intracerebroventricular infusion with either oPRL $(A)$ or antisense ODN against the PRL-R $(B)$. Blood samples were collected under basal conditions and 5, 15 , and 60 min after exposure to the EPM (arrows). $A$, Chronic intracerebroventricular $o P R L\left(5 \mathrm{~d}\right.$; osmotic minipump; $1.0 \mu \mathrm{g} \cdot 0.5 \mu \mathrm{l}^{-1} \cdot \mathrm{hr}^{-1}$ )attenuated stress-induced secretion of ACTH. $B$, Chronic intracerebroventricular PRL-R antisense ODN (PRL-R-AS) (5 d; osmotic minipump; $0.5 \mu \mathrm{g} \cdot 0.5 \mu \mathrm{l}^{-1} \cdot \mathrm{hr}^{-1}$ ) further elevated the stress-induced ACTH response to EPM exposure compared with mixed bases $(M B)$ and vehicle treatment. Insets show the stress-induced rise (percentage of basal) in ACTH secretion. Data are the mean \pm SEM. ${ }^{*} p<0.05,{ }^{*} p<0.01$ versus vehicle/MB; \# $p<0.05$, \#\# $p<0.01$ versus respective basal values.

by molecular modeling succeeded in increasing downregulation efficacy of PRL-R binding when antisense targeting was performed in vivo.

The behavioral and neuroendocrine responses to intracerebral PRL and antisense targeting, respectively, suggest a critical involvement of brain PRL-R. PRL-R expression in the rat brain has been described recently (Chiu and Wise, 1994; Bakowska and Morrell, 1997). Moreover, hypothalamic expression of PRL (Emanuele et al., 1992) and PRL release from hypothalamic explants in response to depolarizing media and angiotensin II (DeVito et al., 1991; Torner et al., 1995) have been observed. This points toward the possibility of intracerebral PRL release, which may occur for example under stressful conditions, as found for various other neuropeptides such as vasopressin and oxytocin (Landgraf, 1995). In our study, to reveal receptor-mediated actions of PRL in the brain in the absence of a specific PRL-R antagonist, we used several complementary approaches. First, an acute intracerebroventricular infusion of oPRL caused a dose-
A
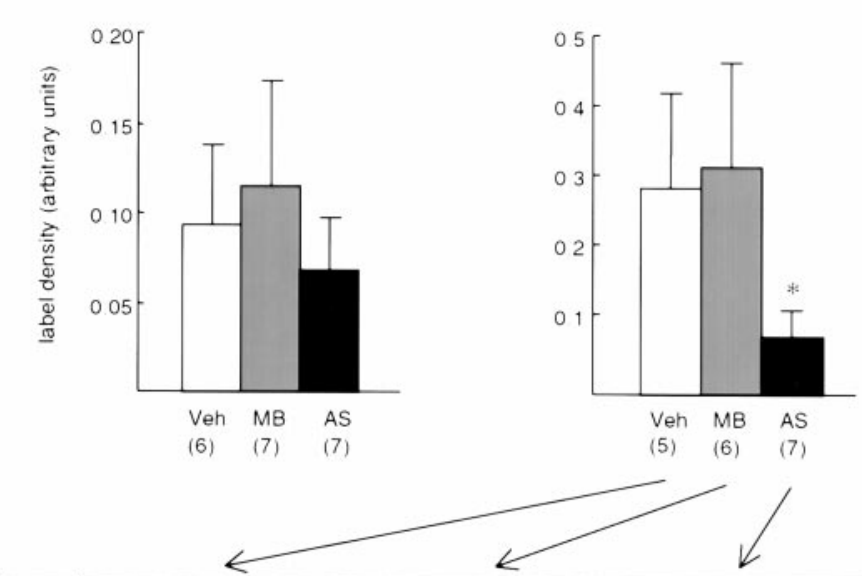

Figure 5. PRL-R binding at the choroid plexus after chronic treatment with PRL-R antisense ODN. $A$, Treatment with empirically designed antisense ODN $(A S 1)$ directed against the PRL-R mRNA resulted in a downregulation of PRL-R binding of $\sim 30 \%$ (n.s.) compared with vehicle $(V e h)$ and mixed bases $(M B) . B$, Treatment with an AS selected on the basis of mRNA secondary structure prediction $(A S 2)$ (Fig. 1) resulted in a downregulation of PRL-R binding of $\sim 72 \%\left({ }^{*} p<0.05\right.$ vs $V e h$ and $\left.M B\right)$. Shown are relative label density values in arbitrary units, obtained from optical density values measured at the choroid plexus of the right cerebral ventricle by appropriate logarithmic transformation. $C$, Distribution of binding sites in the choroid plexus of Veh-, $M B$-, and $A S 2$-treated virgin female rats. Autoradiograms illustrate total binding $(T B)$ and nonspecific binding (NSB).

dependent reduction in anxiety-related behavior on the EPM, the standard test validated for the detection of emotional responses to anxiolytic or anxiogenic substances in rodents (Pellow et al., 1985). Second, an intravenous injection of oPRL also exerted an anxiolytic effect, consistent with the hypothesis of an active and selective uptake of circulating PRL by choroid plexus cells into the cerebrospinal fluid (Walsh et al., 1987). Third, the reverse effect, i.e., an increased anxiety-related behavior on the EPM, was observed after downregulation of PRL-R expression by antisense targeting, further supporting an anxiolytic action of the brain PRL system.

It is worth mentioning that the involvement of PRL in the regulation of anxiety-related behavior does not seem to be restricted to female rats, because an anxiolytic effect of intracerebroventricular oPRL was also found in male rats, although to a lesser extent (Fig. 2B). Several studies addressing behavioral effects of PRL have also demonstrated PRL actions in both genders (Li et al., 1995; Heil, 1999). PRL-R have been mapped in the brain of both female (Crumeyrolle-Arias et al., 1993; Chiu and Wise, 1994; Bakowska and Morrell, 1997; Pi and Grattan, 1998, 1999) and male rats (Muccioli et al., 1991; Roky et al., 1996; Pi and Grattan, 1998). However, evidence exists for a higher 
density of PRL-R in the female rat brain compared with the male (Muccioli et al., 1991; Pi and Grattan, 1998), and this could account for the difference in the anxiolytic potency of oPRL between female and male rats found in the present study. Genderdependent effects of established anxiolytic drugs such as diazepam have also been described (Fernandez-Guasti and Picazo, 1990,1997 ) and could be confirmed in our study (Fig. $2 A, B$ ). It is of interest to note that, in contrast to PRL, diazepam seems to be more efficient in male rats, indicating different mechanisms of action. The finding of reduced locomotor activity after intracerebral PRL during both EPM (Fig. 2) and open-field (Table 1) exposure confirms recent observations in female rats (Alvarez and Banzan, 1994). Interestingly, during 10 min forced swimming, PRL-treated rats showed a more active stress-coping strategy; for example, the latency to floating was prolonged, and the time spent struggling was increased (Table 1), which strengthens the hypothesis of an antidepressive-like action of PRL that has been suggested by Drago et al. (1990).

A possible involvement of PRL in the regulation of emotionality is supported by recent animal (Steimer et al., 1997; Landgraf et al., 1999) and human (Baumgartner et al., 1988; Reavley et al., 1997) studies demonstrating, for example, differing plasma PRL concentrations in rats bred for either high or low innate levels of anxiety-related behavior (Landgraf et al., 1999) or for high and poor acquisition of active avoidance behavior (Steimer et al., 1997). During lactation, when the brain PRL receptors are upregulated (Pi and Grattan, 1999), reduced anxiety scores were reported in various species, including humans (Asher et al., 1995).

Emotional aberrations, in particular an increased level of anxiety, are often accompanied by an enhanced reactivity of the HPA axis (Holsboer and Barden, 1996; Arborelius et al., 1999; Landgraf et al., 1999). In the present study, brain PRL was also shown to regulate $\mathrm{ACTH}$ secretion. Chronic intracerebroventricular oPRL infusions, mimicking a hyperprolactinemic state and presumably resulting in enhanced brain PRL-R expression measurable in the choroid plexus (Mangurian et al., 1992; Sugiyama et al., 1994), caused a shift of HPA axis activity toward elevated basal ACTH plasma concentrations and an attenuated ACTH secretory response to exposure to an emotional stressor. In contrast, downregulation of brain PRL-R expression and, consequently, PRL-R binding by antisense ODN targeting were accompanied by a higher magnitude of ACTH secretory stress responses, underlining the PRL-R-mediated "anti-stress" effect. An explanation for the elevated basal plasma ACTH secretion is provided by the finding of a PRL-induced CRH release into the hypophysial portal blood under basal conditions (Kooy et al., 1990), possibly mediated by the noradrenergic system at hypothalamic level (Calogero et al., 1996). An attenuated responsiveness of the HPA axis is seen in lactation (Walker et al., 1995; Windle et al., 1997; Neumann et al., 2000), a time when the brain PRL system is activated as shown, for example, by an increase in brain PRL-R expression (Pi and Grattan, 1999). Thus, PRL either released into blood and transported to the CSF via choroid plexus cells or released within the brain might be significantly involved in the blunted HPA response observed in lactation.

Supporting our hypothesis of PRL regulating stress responses, chronic restraint stress induces the expression of PRL-R in choroid plexus cells probably because of stress-induced PRL secretion (Fujikawa et al., 1995); administration of PRL into the cerebral ventricles prevents stress-induced hyperthermia (Drago and Amir, 1984) and formation of gastric ulcers (Drago et al., 1985). Furthermore, neuroendocrine stress responses are attenu- ated in hyperprolactinemia (Schlein et al., 1974; Carter and Lightman, 1987).

Because a PRL-R antagonist is lacking, we selectively inhibited the translation of its receptor mRNA using antisense targeting. The approach of intracerebroventricular infusion of an antisense ODN has been recognized as a useful tool to evaluate the function of a given neuropeptide system, because ODN diff usion to, for example, extrahypothalamic and hypothalamic regions has been described in the rat brain (Wahlestedt et al., 1993). However, a major problem of antisense targeting is the position of the target site within the mRNA molecule (Patzel and Sczakiel, 1998). In the present study this critical issue was successfully addressed by performing a computer-assisted prediction of the secondary structure exhibited by the target mRNA, hence applying recently established criteria that describe the influence of mRNA self-structure on hybridization (Mir and Southern, 1999). A modeling approach is currently the only way of accessing structural information, because x-ray crystallography or nuclear magnetic resonance techniques are still not feasible for large chain lengths. Changing the target position from empirically selected sites that are predicted to include fractions of helical stems (Fig. $1 A$ ) to one that is expected to form a complete stem, an internal loop, and a hairpin loop (Fig. $1 B$ ) significantly increased the treatment efficiency. Here it should be mentioned that (1) the different length of the ODNs (18 vs 20 bases), (2) possible differences in self-complementarity of the molecules, and (3) presence of two separate molecules in the AS1 mixture could have intrinsically affected the relative efficiency of the treatments, regardless of the structural considerations. However, given the well known rarity of highly efficient antisense molecules, the differences in predicted molecular structures of the target regions should be made responsible for the largest portion of the improvement in treatment efficiency presented here. Receptor autoradiography confirmed the expected improvement in downregulation efficiency in vivo after molecular modeling (30 vs $72 \%$ in the choroid plexus after adjustment of target positioning).

Quantification of antisense ODN-induced downregulation of PRL-R binding was performed over the choroid plexus, where labeling was strongest. Significant PRL-R binding was not detected in other relevant brain regions, possibly resulting from either low brain density of PRL-R (Muccioli et al., 1991) and lack of respective sensitivity of the receptor autoradiography used or occupancy of brain PRL-R by endogenous PRL, because decapitation of the animals was performed $1 \mathrm{hr}$ after stressor exposure. However, extensive brain penetration and cellular uptake have been demonstrated using the route of continuous intracerebroventricular antisense ODN administration (Whitesell et al., 1993). Therefore, the behavioral and neuroendocrine effects seen in PRL-R antisense-treated animals are likely to be caused by downregulation of PRL-R expression in relevant brain regions, including the hypothalamic PVN, amygdala, and septal nuclei. In these regions, interactions with the $\mathrm{CRH}$ system have to be considered in future studies. An alternative explanation for the antisense effects that were observed, however, would be a reduced uptake of circulating PRL into CSF and, consequently, to the brain as a result of downregulation of PRL-R expression and receptor-mediated transport processes in the choroid plexus. This hypothesis includes questions regarding the origin of the endogenous ligand of brain PRL-R because PRL may reach relevant brain targets after either selective uptake by choroid plexus cells or local release from neuronal structures. The latter question is 
currently under investigation using intracerebral microperfusion techniques.

We propose that the complementary methodological approach used to specifically modulate brain neuropeptide-receptor interactions, both increasing the availability of the receptor ligand and reducing neuropeptide receptor expression by antisense targeting, is still a valid alternative to genetic knockout strategies for the characterization of novel physiological functions of any neuropeptidergic system. However, more work, including additional behavioral tests and characterization of detailed PRL interactions with other relevant neuropeptides such as $\mathrm{CRH}$, will be required to further establish the general role of brain PRL in the regulation of both emotionality and neuroendocrine stress coping at brain level.

\section{REFERENCES}

Abel EL (1994) A further analysis of physiological changes in rats in the forced swim test. Physiol Behav 56:795-800.

Alvarez EO, Banzan AM (1994) Behavioural actions of prolactin locally applied into the hippocampus of adult female rats. J Neural Transm Gen Sect 95:17-28.

Arborelius L, Owens MJ, Plotsky PM, Nemeroff CB (1999) The role of corticotropin-releasing factor in depression and anxiety disorders. J Endocrinol 160:1-12.

Asher I, Kaplan B, Modai I, Neri A, Valevski A, Weizman A (1995) Mood and hormonal changes during late pregnancy and puerperium. Clin Exp Obstet Gynecol 22:321-325.

Bakowska JC, Morrell JI (1997) Atlas of the neurons that express mRNA for the long form of the prolactin receptor in the forebrain of the female rat. J Comp Neurol 386:161-177.

Baumgartner A, Graf K, Kurten I (1988) Prolactin in patients with major depressive disorder and in healthy subjects. I. Cross-sectional study of basal and post-TRH and postdexamethasone prolactin levels. Biol Psychiatry 24:249-267.

Breton N, Jacob C, Daegelen P (1997) Prediction of sequentially optimal RNA secondary structures. J Biomol Struct Dyn 14:727-739.

Bridges RS, Numan M, Ronsheim PM, Mann PE, Lupini CE (1990) Central prolactin infusions stimulate maternal behavior in steroidtreated, nulliparous female rats. Proc Natl Acad Sci USA 87:8003-8007.

Cairns MJ, Hopkins TM, Witherington C, Wang L, Sun LQ (1999) Target site selection for an RNA-cleaving catalytic DNA. Nat Biotechnol 17:480-486.

Calogero AE, Burrello N, Ossino AM, Weber RFA, D’Agata R (1996) Interaction between prolactin and catecholamines on hypothalamic GnRH release in vitro. J Endocrinol 151:269-275.

Carter DA, Lightman SL (1987) Oxytocin responses to stress in lactating and hyperprolactinemic rats. Neuroendocrinology 46:532-537.

Charney DS, Grillon CCG, Bremner JD (1998) The neurobiological basis of anxiety and fear: circuits, mechanisms, and neurochemical interactions (Part II). The Neuroscientist 4:122-132.

Chiu S, Wise PM (1994) Prolactin receptor mRNA localization in the hypothalamus by in situ hybridization. J Neuroendocrinol 6:191-199.

Clapp C, Torner L, Gutierrez-Ospina G, Alcantara E, Lopez-Gomez FJ, Nagano M, Kelly PA, Mejia S, Morales MA, Martinez de la Escalera G (1994) The prolactin gene is expressed in the hypothalamicneurohypophyseal system and the protein is processed into a $14-\mathrm{kDa}$ fragment with activity like $16-\mathrm{kDa}$ prolactin. Proc Natl Acad Sci USA 91:10384-10388.

Crumeyrolle-Arias M, Latouche J, Jammes H, Djiane J, Kelly PA, Reymond HJ, Haour F (1993) Prolactin receptors in the rat hypothalamus: autoradiographic localization and characterization. Neuroendocrinology 57:457-466.

DeVito WJ, Stone S, Avakian C (1991) Stimulation of hypothalamic prolactin release by veratridine and angiotensin II in the female rat: effect of ovariectomy and estradiol administration. Neuroendocrinology 54:391-398.

DeVito WJ, Avakian C, Stone S, Ace CI (1992) Estradiol increases prolactin synthesis and prolactin messenger ribonucleic acid in selected brain regions in the hypophysectomized female rat. Endocrinology $131: 2154-2160$.

Drago F, Amir S (1984) Effects of hyperprolactinemia on core temperature of the rat. Brain Res Bull 12:355-358.

Drago F, Bohus B, Gispen WH, Scapagnini U, De Wied D (1983) Prolactin-enhanced grooming behavior: interaction with ACTH. Brain Res 263:277-282.

Drago F, Continella G, Conforto G, Scapagnini U (1985) Prolactin inhibits the development of stress-induced ulcers in the rat. Life Sci 36:191-197.

Drago F, Pulvirenti L, Spadaro F, Pennisi G (1990) Effects of TRH and prolactin in the behavioral despair (swim) model of depression in rats. Psychoneuroendocrinology 15:349-356.

Emanuele NV, Jurgens JK, Halloran MM, Tentler JJ, Lawrence AM, Kelley MR (1992) The rat prolactin gene is expressed in brain tissue: detection of normal and alternatively spliced prolactin messenger RNA. Mol Endocrinol 6:35-42.

Fernandez-Guasti A, Picazo O (1990) The actions of diazepam and serotonergic anxiolytics vary according to the gender and the estrous cycle phase. Pharmacol Biochem Behav 37:77-81.

Fernandez-Guasti A, Picazo O (1997) Anxiolytic actions of diazepam, but not buspirone, are influenced by gender and the endocrine stage. Behav Brain Res 88:213-218.

Fujikawa T, Soya H, Yoshizato H, Sakaguchi K, Doh-Ura K, Tanaka M, Nakasima K (1995) Restraint stress enhances the gene expression of prolactin receptor long form at the choroid plexus. Endocrinology 136:5608-5613.

Heil SH (1999) Sex-specific effects of prolactin on food intake by rats. Horm Behav 35:47-54.

Ho SP, Bao Y, Lesher T, Malhotra R, Ma LY, Fluharty SJ, Sakai RR (1998) Mapping of RNA accessible sites for antisense experiments with oligonucleotide libraries. Nat Biotechnol 16:59-63.

Holsboer F, Barden N (1996) Antidepressants and hypothalamicpituitary-adrenocortical regulation. Endocr Rev 17:187-205.

Kooy A, deGreef WJ, Vreeburg JTM, Hackeng WHL, Ooms MP, Lamberts SWJ, Weber RFA (1990) Evidence for the involvement of corticotropin-releasing factor in the inhibition of gonadotropin release induced by hyperprolactinemia. Neuroendocrinology 51:261-266.

Kramer MS, Cutler N, Feghner J, Shrivastava R, Carman J, Sramek JJ, Reines SA, Liu G, Snavely D, Wyatt-Knowles E, Hale JJ, Mills SG, MacCoss M, Swain CJ, Harrison T, Hill RG, Hefti F, Scolnick EM, Chicchi GG, Sadowski S, Williams AR, Hewson L, Smith D, Carlson EJ, Hargreaves RJ, Rupniak NMJ (1998) Distinct mechanism for antidepressant activity by blockade of central substance $\mathrm{P}$ receptors. Science 281:1640-1645

Landgraf R (1995) Intracerebrally released vasopressin and oxytocin: measurement, mechanisms and behavioural consequences. J Neuroendocrinol 7:243-253.

Landgraf R, Wigger A, Holsboer F, Neumann ID (1999) Hyper-reactive hypothalamo-pituitary-adrenocortical axis in rats bred for high anxietyrelated behavior. J Neuroendocrinol 11:405-407.

Li C, Kelly PA, Buntin JD (1995) Inhibitory effects of anti-prolactin receptor antibodies on prolactin binding in brain and prolactin-induced feeding behavior in ring doves. Neuroendocrinology 61:125-135.

Liebsch G, Wotjak CT, Landgraf R, Engelmann M (1996) Septal vasopressin modulates anxiety-related behavior in rats. Neurosci Lett 217:101-104.

Liebsch G, Linthorst ACE, Neumann ID, Reul JMHM, Holsboer F, Landgraf R (1998) Behavioral, physiological, and neuroendocrine stress responses and differential sensitivity to diazepam in two Wistar rat lines selectively bred for high- and low-anxiety-related behavior. Neuropsychopharmacology 19:381-396.

Lucas BK, Ormandy CJ, Binart N, Bridges RS, Kelly PA (1998) Null mutation of the prolactin receptor gene produces a defect in maternal behavior. Endocrinology 139:4102-4107.

Mangurian LP, Walsh RJ, Posner BI (1992) Prolactin enhancement of its uptake at the choroid plexus. Endocrinology 131:698-702.

Marti J, Armario A (1993) Effects of diazepam and desipramine in the forced swimming test: influence of previous experience with the situation. Eur J Pharmacol 236:295-299.

Merchenthaler I, Vigh S, Petrusz P, Schally A (1982) Immunocytochemical localization of corticotropin releasing factors (CRF) in the rat brain. Am J Anat 165:385-396.

Mir KU, Southern EM (1999) Determining the influence of structure on hybridization using oligonucleotide arrays. Nat Biotechnol 17:788-792.

Mitchell AJ (1999) The role of corticotropin releasing factor in depressive illness: a critical review. Neurosci Biobehav Rev 22:635-651.

Muccioli G, Ghe C, Di Carlo R (1991) Distribution and characterization of prolactin binding sites in the male and female rat brain: effects of hypophysectomy and ovariectomy. Neuroendocrinology 53:47-53.

Neill JD (1970) Effects of "stress" on serum prolactin and luteinizing hormone levels during the estrous cycle of the rat. Endocrinology 87:1192-1197.

Neumann ID, Johnstone HA, Hatzinger M, Liebsch G, Shipston M, Russell JA, Landgraf R, Douglas AJ (1998) Attenuated neuroendocrine responses to emotional and physical stressors in pregnant rats involve adenohypophyseal changes. J Physiol (Lond) 508:289-300.

Neumann ID, Torner L, Wigger A (2000) Brain oxytocin: differential inhibition of neuroendocrine stress responses and anxiety-related behaviour in virgin, pregnant and lactating rats. Neuroscience 95:567-575.

Noel MB, Woodside B (1993) Effects of systemic and central prolactin injections on food intake, weight gain, and estrous cyclicity in female rats. Physiol Behav 54:151-154.

Patzel V, Sczakiel G (1998) Theoretical design of antisense RNA structures substantially improves annealing kinetics and efficacy in human cells. Nat Biotechnol 16:64-68. 
Paut-Pagano L, Roky R, Valatx JL, Kitahama K, Jouvet M (1993) Anatomical distribution of prolactin-like immunoreactivity in the rat brain. Neuroendocrinology 58:682-695.

Paxinos G, Watson C (1986) The rat brain in stereotaxic coordinates. Sydney: Academic.

Pellow S, Chopin P, File SE, Briley M (1985) Validation of open:closed arms entries in an elevated plus-maze as a measure of anxiety in the rat. J Neurosci Methods 14:149-167.

Pi XJ, Grattan DR (1998) Distribution of prolactin receptor immunoreactivity in the brain of estrogen-treated, ovariectomized rats. J Comp Neurol 394:462-474.

Pi XJ, Grattan DR (1999) Increased prolactin receptor immunoreactivity in the hypothalamus of lactating rats. J Neuroendocrinol 11:693-705.

Reavley S, Fisher AD, Owen D, Creed FH, Davis JRE (1997) Psychological distress in patients with hyperprolactinemia. Clin Endocrinol (Oxf) 47:343-348.

Roky R, Paut-Pagano L, Goffin V, Kitahama K, Valatx JL, Kelly PA, Jouvet M (1996) Distribution of prolactin receptors in the rat forebrain. Immunohistochemical study. Neuroendocrinology 63:422-429.

Schlein PA, Zarrow MX, Denenberg VH (1974) The role of prolactin in the depressed or "buffered" adrenocorticosteroid response of the rat. J Endocrinol 62:93-99.

Seggie JA, Brown GM (1975) Stress response patterns of plasma corticosterone, prolactin, and growth hormone in the rat, following handling or exposure to novel environment. Can J Physiol Pharmacol 53:629-637.

Shirota M, Banville D, Ali S, Jolicoeur C, Boutin J-M, Edery M, Djane J, Kelly PA (1990) Expression of two forms of prolactin receptor in rat ovary and liver. Mol Endocrinol 4:1136-1143.

Steimer T, la Fleur S, Schulz PR (1997) Neuroendocrine correlates of emotional reactivity and coping in male rats from the Roman high (RHA/Verh)- and low (RLA/Verh)- avoidance lines. Behav Genet 27:503-512.
Sugiyama T, Minoura H, Kawabe N, Tanaka M, Nakashima K (1994) Preferential expression of long form prolactin receptor mRNA in the rat brain during the estrous cycle, pregnancy and lactation: hormones involved in its gene expression. J Endocrinol 141:325-333.

Torner L, Neumann I (1998) Effects of intracerebral prolactin on anxiety-related behavior and HPA axis activity in rats. Soc Neurosci Abstr 371:19.

Torner L, Mejia S, Lopez-Gomez FJ, Quintanar A, Martinez de la Escalera G, Clapp C (1995) A 14-kilodalton prolactin-like fragment is secreted by the hypothalamo-neurohypophyseal system of the rat. Endocrinology 136:5454-5460.

Torner L, Toschi N, Pohlinger A, Probst JC, Lörscher P, Neumann I (1999) Blockade of prolactin (PRL) receptors by antisense targeting and icv infusion of PRL affect anxiety-related behavior and neuroendocrine responses to stress. Soc Neurosci Abstr 64:8.

Wahlestedt C, Merlo-Pich E, Koob GF, Yee F, Heilig M (1993) Modulation of anxiety and neuropeptide Y-Y1 receptors by antisense oligodeoxynucleotides. Science 259:528-531.

Walker CD, Trottier G, Rochford J, Lavallée D (1995) Dissociation between behavioral and hormonal responses to the forced swim stress in lactating rats. J Neuroendocrinol 7:615-622.

Walsh RJ, Slaby FJ, Posner BI (1987) A receptor-mediated mechanism for the transport of prolactin from blood to cerebrospinal fluid. Endocrinology 120:1846-1850.

Whitesell L, Geselowitz D, Chavany C, Fahmy B, Walbridge S, Alger JR, Neckers LM (1993) Stability, clearance, and disposition of intraventricularly administered oligodeoxynucleotides: implications for therapeutic application within the central nervous system. Proc Natl Acad Sci USA 90:4665-4669.

Windle RJ, Wood S, Shanks N, Perks P, Conde GL, da Costa APC, Ingram CD, Lightman SL (1997) Endocrine and behavioural responses to noise stress: comparison of virgin and lactating female rats during non-disrupted maternal activity. J Neuroendocrinol 9:407-414. 